\title{
Multidimensional Poverty Index 2014: Brief Methodological Note and Results
}

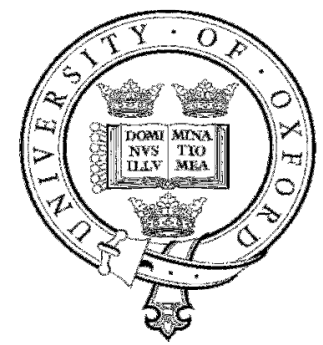

\author{
Sabina Alkire*, Adriana Conconi* and Suman Seth*
}

June 2014

\section{Acknowledgements}

We warmly acknowledge the contribution of many colleagues and co-workers who participated in the update of the MPI in 2014. In particular, we are grateful to our colleagues at the HDRO for their substantive engagement, especially Milorad Kovacevic, Cecilia Calderon and Khalid Malik. We are grateful as well to Rolf Luyendijk at UNICEF and to Sunita Kishor, Shea Rutstein and Trevor Croft at DHS/ICFI for answering some survey-related queries, and to Enrique González Tiburcio for his support. We are deeply appreciative of the competent support at some stages of new MPI calculations from Ivan Gonzalez de Alba, Aparna John, Usha Kanagaratnam, Saite Lu, Maria Mancilla Garcia, Christian Oldiges, Felipe Roa-Clavijo and Quang Van Tran. We acknowledge warmly the work of Ana Vaz who led the 2014 calculations and analyses on changes over time for MPI and destitution (national and by groups). We also wish to thank Mihika Chatterjee and Ana Vaz for their substantive input and suggestions throughout the process. We also wish to thank other OPHI team members and associates, Mauricio Apablaza, Paola Ballon, Paddy Coulter, Emma Feeny, Heidi Fletcher, James Foster, Natasha Francis, John Hammock, Bouba Housseini, Laura O’Mahony, China Mills, Jose Manuel Roche, Maria Emma Santos, Moizza B Sarwar, Gaston Yalonetzky and Diego Zavaleta, for their support and substantive input. We also wish to thank special advisors on additional topics or datasets including Yele Batana, Stefan Dercon, Paulo de Martino Jannuzzi, Zhou Liang, Maria Auxiliadora Lopez, Marcelo Cortes Neri, Philomena Nyarko, Abena Asamoabea Osei-Akoto, Catherine Porter, Anthnony Pharin, Xiaolin Wang, and Shen Yangyang. All errors remain our own.

This analysis uses data from the USAID Demographic and Health Surveys (DHS), UNICEF Multiple Indicator Cluster Surveys (MICS), WHO World Health Surveys and special national household surveys.

\footnotetext{
* The Oxford Poverty and Human Development Initiative (OPHI), Oxford Department of International Development, University of Oxford. Contact details: ophi@qeh.ox.ac.uk Tel +44 1865271915 Fax +44 (0)1865 281801
}

This note has been prepared within the OPHI theme on [multidimensional poverty measurement.

OPHI gratefully acknowledges support from the UK Economic and Social Research Council (ESRC)/(DFID) Joint Scheme, Robertson Foundation, Praus, UNICEF N'Djamena Chad Country Office, German Federal Ministry for Economic Cooperation and Development (BMZ), Georg-August-Universität Göttingen, International Food Policy Research Institute (IFPRI), John Fell Oxford University Press (OUP) Research Fund, United Nations Development Programme (UNDP) Human Development Report Office, national UNDP and UNICEF offices, and private benefactors. International Development Research Council (IDRC) of Canada, Canadian International Development Agency (CIDA), UK Department of International Development (DFID), and AusAID are also recognised for their past support. 


\section{Contents}

Introduction 2

1. 2014 Updates to the MPI 2

2. The MPI Methodology: Poverty, Vulnerability, and Severe Poverty 3

3. The Measurement of Destitution 5

4. Inequality among the poor 6

5. Changes over Time $\quad 7$

$\begin{array}{lr}\text { 6. Considerations by country } & 8\end{array}$

\section{Introduction}

The Multidimensional Poverty Index (MPI) 2014 uses the same parameters (dimensions, indicators, cutoffs and weights) and the same functional form (Alkire and Foster Adjusted Headcount Ratio $\mathrm{M}_{0}$ ) as in previous years. The main innovations this year consist in: updating the estimations for a larger series of countries than any previous year, providing further analysis over time, as well as a new measure of destitution, and new measures of inequality among the poor and across subnational regions. This brief methodological note presents the MPI 2014 measures, and the tables with the full results. It first explains the main updates in the MPI 2014, following the guidelines for updates presented in the 2013 Methodological Note (Alkire, Conconi and Roche 2013). It summarizes the MPI methodology that has been presented in detail in other documents (Alkire and Santos 2010; Alkire, Roche, Santos and Seth 2011). Then it explains the new measure of destitution, which uses the same dimensions, indicators and weights, but more extreme deprivation cutoffs. Finally, a brief description of the index on inequality among the poor is presented. The methodologies used to generate the tables on the MPI and the 108 country briefings and interactive maps available on OPHI's website, as well as the results to be published in the 2014 Human Development Report, are presented in this note. The tables are presented as appendices and are available for download as Excel files.

\section{2014 Updates to the MPI}

\section{Updated MPIs from new data and discontinued countries}

The MPI 2014 has new and updated estimations with more recent data for 33 countries; in 2013 there were updates for 16 countries and in 2011, for 25 countries. At present, data for 49 of the 108 countries were collected in or after 2010, and data for 60 countries were collected during or after 2008.

The countries in 2014, together with the surveys used and years are as follows. ${ }^{1}$ New countries: Afghanistan (MICS 2010/11), Guinea-Bissau (MICS 2006). Updated countries: Bangladesh (DHS 2011), Belize (MICS 2011), Bosnia and Herzegovina (MICS 2011/12), Burundi (DHS 2010), Cameroon (DHS 2011), Central African Republic (MICS 2010), Republic of Congo (DHS 2011/12), Cote d'Ivoire (DHS 2011/12), Gabon (DHS 2012), Ghana (MICS 2011), Haiti (DHS 2012), Honduras (DHS 2011/12), Indonesia (DHS 2012), Iraq (MICS 2011), Kazakhstan (MICS 2010/11), Lao PDR (MICS-

\footnotetext{
1 Recent surveys for other countries/years were also considered but eventually dismissed from the calculations of the MPI 2014 because they do not satisfy the policies for updating, as explained in the 2013 Methodological Note (e.g. Belarus's MICS 2012, Cuba's MICS 2010/11, etc.).
} 
DHS 2011/12), TFYR of Macedonia (MICS 2011), Mexico (ENSANUT 2012), Mozambique (DHS 2011), Nicaragua (DHS 2011/12), Niger (DHS 2012), Nigeria (MICS 2011), Pakistan (DHS 2012/13), Peru (DHS-Continuous 2012), Serbia (MICS 2010), Sierra Leone (MICS 2010), South Africa (NIDS 2012), Suriname (MICS 2010), Tajikistan (DHS 2012), Togo (MICS 2010), and Tunisia (MICS 2010/12).

The MPI has a moving 'oldest country' category. In 2013, we reported MPI estimations using data from 2002-2011; in 2011 from 2000-2010; in 2010 from 2000-2008; and in 2014 we report estimations from 2003-2012/13, except that we include China's WHS because it was fielded in 2002, whereas WHS surveys were otherwise fielded in 2003. No countries were dropped from the 2013 MPI figures.

\section{Policies regarding population figures and complementary information}

As stated in the 2013 Methodological Note, the surveys are dated according to the year in which the fieldwork took place, as detailed in the data report. If the fieldwork took place during two calendar years, the data will be labelled with both years, e.g. 2010/11.

In this case, the population figures indicated as those of the year of the survey, as well as the complementary information, will correspond to the second calendar year, or the closest available year with information. ${ }^{2}$

Population figures are also reported for 2010 and 2011, using the 2012 Revision of World Population Prospects (UNDESA 2013). When, for illustrative purposes, regional aggregates are presented, 2010 population data are employed. Aggregate estimates in 2013 used 2009 population data. The population year used for aggregate estimates changes by one year annually.

\section{The MPI Methodology: Poverty, Vulnerability, and Severe Poverty}

The MPI is a measure of acute global poverty developed by the Oxford Poverty and Human Development Initiative (OPHI) with the United Nations Development Programme's Human Development Report (see for details, Alkire and Santos 2010, 2014; Alkire et al. 2011, 2013; UNDP 2010). The index belongs to the family of measures developed by Alkire and Foster (2007, 2011). In particular, it is an application of the adjusted headcount ratio, $M_{0}$. This methodology requires determining the unit of analysis (i.e. household), identifying the set of indicators in which they are deprived at the same time and summarizing their poverty profile in a weighted deprivation score. They are identified as multidimensionally poor if their deprivation score exceeds a cross-dimensional poverty cutoff. The number of poor people and their deprivation score (i.e. the 'intensity' of poverty or percentage of simultaneous deprivations they experience) become part of the final poverty measure. A more formal explanation of the methodology is presented in Alkire and Santos (2014) and in Alkire and Foster (2011).

\footnotetext{
2 The population figures and complementary information was modified following this criteria in a few countries presented in previous rounds of the MPI. These include India, Montenegro and Thailand (in which cases the information was updated from 2005 to 2006), and Timor-Leste (from 2009 to 2010). The MPI estimations were not altered.
} 
Table 1: The dimensions, indicators, deprivation cutoffs and weights of the MPI

\begin{tabular}{|c|c|c|c|}
\hline $\begin{array}{l}\text { Dimensions } \\
\text { of poverty }\end{array}$ & Indicator & Deprived if... & Weight \\
\hline \multirow{2}{*}{ Education } & Years of Schooling & No household member has completed five years of schooling. & $1 / 6$ \\
\hline & Child School Attendance & Any school-aged child is not attending school up to class 8 . & $1 / 6$ \\
\hline \multirow{2}{*}{ Health } & Child Mortality & Any child has died in the family. & $1 / 6$ \\
\hline & Nutrition & $\begin{array}{l}\text { Any adult or child for whom there is nutritional information is } \\
\text { malnourished. }\end{array}$ & $1 / 6$ \\
\hline \multirow{6}{*}{ Living Standard } & Electricity & The household has no electricity. & $1 / 18$ \\
\hline & Improved Sanitation & $\begin{array}{l}\text { The household's sanitation facility is not improved (according to MDG } \\
\text { guidelines), or it is improved but shared with other households. }\end{array}$ & $1 / 18$ \\
\hline & Improved Drinking Water & $\begin{array}{l}\text { The household does not have access to improved drinking water } \\
\text { (according to MDG guidelines) or safe drinking water is more than a } \\
\text { 30-minute walk from home, roundtrip. }\end{array}$ & $1 / 18$ \\
\hline & Flooring & The household has a dirt, sand or dung floor. & $1 / 18$ \\
\hline & Cooking Fuel & The household cooks with dung, wood or charcoal. & $1 / 18$ \\
\hline & Assets ownership & $\begin{array}{l}\text { The household does not own more than one radio, TV, telephone, bike, } \\
\text { motorbike or refrigerator and does not own a car or truck. }\end{array}$ & $1 / 18$ \\
\hline
\end{tabular}

Note: Further details in Table Annex A.1.

The 2014 global MPI assesses multidimensional poverty for people in 108 developing countries for which data from 2002 onwards are available. ${ }^{3}$ As summarized in Table 1, the MPI uses information from 10 indicators which are organised into three dimensions: ${ }^{4}$ health, education and living standards, following the same dimensions and weights as the Human Development Index (HDI). Each person is identified as deprived or non-deprived in each indicator based on a deprivation cutoff (more details in Alkire and Santos 2010). Health and Education indicators reflect achievements of all household members. Then, each person's deprivation score is constructed based on a weighted average of the deprivations they experience using a nested weight structure: equal weight across dimension and equal weight for each indicator within dimensions. Finally, a poverty cutoff of $33.33 \%$ identifies as multidimensionally poor those people whose deprivation score meets or exceeds this threshold.

The MPI reflects both the incidence or headcount ratio $(H)$ of poverty - the proportion of the population that is multidimensionally poor - and the average intensity $(A)$ of their poverty - the average proportion of indicators in which poor people are deprived. The MPI is calculated by multiplying the incidence of poverty by the average intensity across the poor $(H \times A)$. A person is identified as poor if he or she is deprived in at least one third of the weighted indicators. Those identified as 'Vulnerable to Poverty' are deprived in 20\% $-33.33 \%$ of weighted indicators and those identified as in 'Severe Poverty' are deprived in $50 \%$ or more of the dimensions.

3 MPI estimations prior to 2002 are available for an additional three countries (Angola, Comoros and Myanmar).

${ }^{4}$ For a more detailed description of the indicator definitions, see Alkire and Santos (2010) and Alkire et al. (2011). 


\section{The Measurement of Destitution}

In 2014, to illustrate the ability of the MPI to consider the 'depth' of deprivations rigorously although data may be ordinal, we estimate a new poverty measure which we call destitution. This destitution measure has precisely the same dimensions, indicators, weights, and poverty cutoff as the MPI. Only one set of parameters changes: the deprivation cutoffs. The cutoffs for 8 of the 10 indicators now reflect more extreme deprivations. As a result, the destitution measure identifies a strict subset of the MPI poor who are also deprived in at least one-third of the indicators according to the destitution cutoffs.

That is, those identified as 'Destitute' are deprived in at least one third or more of the same weighted indicators with more extreme deprivation cutoffs (as described in Table 2); for example, two or more children in the household have died, no one in the household has more than one year of schooling, a household member is severely malnourished, or the household practises open defecation. Data on destitution is available for 49 of the 108 countries analysed in the MPI 2014. For detail, see Alkire Conconi \& Seth (2014).

Table 2: The dimensions, indicators, deprivation cutoffs and weights of the Destitute

\begin{tabular}{|c|c|c|}
\hline $\begin{array}{l}\text { Dimensions of } \\
\text { poverty (same as for } \\
\text { standard MPI) }\end{array}$ & $\begin{array}{l}\text { Indicator (same as for } \\
\text { standard MPI) }\end{array}$ & Deprived if... \\
\hline \multirow{2}{*}{ Education } & Years of Schooling & No household member has completed at least one year of schooling. \\
\hline & Child School Attendance & $\begin{array}{l}\text { No children are attending school up to the age at which they should finish } \\
\text { class } 6 \text {. }\end{array}$ \\
\hline \multirow{2}{*}{ Health } & Child Mortality & 2 or more children have died in the household. \\
\hline & Nutrition & $\begin{array}{l}\text { Severe undernourishment of any adult }\left(\mathrm{BMI}<17 \mathrm{~kg} / \mathrm{m}^{2}\right) \text { or any child } \\
\text { (-3 standard deviations from the median). }\end{array}$ \\
\hline \multirow{6}{*}{ Living Standard } & Electricity & The household has no electricity (no change). \\
\hline & Improved Sanitation & There is no sanitation facility (open defecation). \\
\hline & Improved Drinking Water & $\begin{array}{l}\text { The household does not have access to safe drinking water, or safe water is } \\
\text { more than a } 45 \text {-minute walk (round trip). }\end{array}$ \\
\hline & Flooring & The household has a dirt, sand, or dung floor (no change). \\
\hline & Cooking Fuel & $\begin{array}{l}\text { The household cooks with dung or wood (coal/lignite/charcoal are now } \\
\text { non-deprived). }\end{array}$ \\
\hline & Assets ownership & $\begin{array}{l}\text { The household has no assets (radio, mobile phone, refrigerator, etc.) } \\
\text { and no car. }\end{array}$ \\
\hline
\end{tabular}

Note: Further details in Table Annex A.2. 


\section{Inequality among the poor}

Although the ultimate goal is to alleviate poverty, it is important to understand if the fruit of poverty alleviation is share by all poor people and by all groups. A drastic reduction in the number of poor or their average intensities may not ensure that those with larger number of multiple deprivations have been benefitted. We attempt to measure the level of inequality in deprivation scores among the poor, both at the national level and within subnational regions, by using a separate, decomposable inequality measure. We also use the measure to assess disparity across subnational MPIs.

In order to fit our goal of studying both inequality among the poor within population subgroups and disparity between population subgroups, Seth and Alkire (2014) proposed an additively decomposable inequality measure. This inequality measure - which is a positive multiple of "variance" - can be broken down into a within-group and a between-group component. For measuring inequality among the poor at the national level, the inequality measure $I^{q}$ uses the vector of deprivation scores of the $q$ poor people $c_{i}(k)$.

$$
I^{q}=\frac{\tilde{\beta}}{q} \sum_{i=1}^{q}\left[c_{i}(k)-A\right]^{2} .
$$

The difference between each poor person's deprivation score and average intensity is squared, and the squared distances summed and multiplied by a constant $\tilde{\beta}$ to create the measure of inequality. The deprivation scores of the poor range between $1 / 3$ and 1 , and so we set $\tilde{\beta}=1 / 9$. This is the maximum possible value the inequality measure can take given the range of deprivation scores and thus ensures that the inequality measure is bounded between zero and one. In practice, in the MPI 2014 estimations, inequality among the poor at the national level varies from 0.006 to 0.300 .

The same measure is used to compute inequality among the poor within each subnational region as

$$
I^{q^{\ell}}=\frac{\tilde{\beta}}{q^{\ell}} \sum_{i=1}^{q^{\ell}}\left[c_{i}(k)-A^{\ell}\right]^{2},
$$

where $q^{\ell}$ is the number of poor in subgroup $\ell$ and $A^{\ell}$ is the average intensity within that subgroup. As earlier, in this case, we also choose $\tilde{\beta}=1 / 9$. In the MPI 2014 estimations, inequality among the poor at the subnational level varies from 0 to 0.346 .

A lower level of inequality among the poor or a reduction in the level of inequality among the poor, however, may not mean that poverty has uniformly gone down in all regions or population subgroups. For measuring regional or subnational disparity across MPIs, the MPI of each of the $m$ subnational regions, denoted by $M P I^{\ell}$ (each having a population of $n^{\ell}$ for $\ell=1, \ldots, m$ ) is combined in a similar manner with the national MPI (with population size $n$ ). The measure of subnational disparity is denoted by $I^{M P I}$ and is calculated as

$$
I^{M P I}=\tilde{\beta} \sum_{\ell=1}^{m} \frac{n^{\ell}}{n}\left(M P I^{\ell}-M P I\right)^{2} .
$$

Thus, the difference between each regions MPI and the national MPI is squared, and the populationshare weighted squared distances are summed and multiplied by a constant $\tilde{\beta}$ to create the measure of disparity. In this case, we choose $\tilde{\beta}=1 / 4$ because MPIs range between zero and one. In the MPI 2014 estimations, it varies from zero to 0.144 .

For further details of the measure and how it is applied, see Seth and Alkire (2014), available at http://www.ophi.org.uk/measuring-and-decomposing-inequality-among-the-multidimensionally-poorusing-ordinal-data-a-counting-approach/. 


\section{Changes over Time}

A strong motivation for computing multidimensional poverty is to track and analyse changes over time. This section describes how to compare $M_{0}$ and its associated partial indices (as well as Destitution measures) over time using repeated cross-sectional data, which are the most widely available data. We also compare inequality over time.

The basic component of poverty comparisons is the absolute pace of change across periods. The absolute rate of change is the simple difference in poverty levels between two periods. We denote the initial period by $t^{1}$ and the final period by $t^{2}$, and the corresponding achievement matrices for these two periods by $X_{t^{1}}$ and $X_{t^{2}}$, respectively. The same set of parameters - deprivation cutoff vector $Z$, weight vector $W$ and poverty cutoff $k$-are used in each period.

The absolute rate of change $(\Delta)$ is the difference in MPIs between two periods and is computed as

$$
\Delta M P I=M P I\left(X_{t^{2}}\right)-M P I\left(X_{t^{1}}\right)
$$

Similarly, for $H$ and $A$ :

$$
\begin{gathered}
\Delta H=H\left(X_{t^{2}}\right)-H\left(X_{t^{1}}\right) . \\
\Delta A=A\left(X_{t^{2}}\right)-A\left(X_{t^{1}}\right) .
\end{gathered}
$$

The absolute rate of change is indifferent to the initial level. For example, a 5 percentage point reduction of $\mathrm{H}$ could mean that $\mathrm{H}$ decreased from $75 \%$ to $70 \%$ or from $10 \%$ to $5 \%$. Changes (increases or decreases) in poverty across two time periods are also evaluated using relative rates. The relative rate of change is the difference in poverty as a percentage of the initial poverty level. Interpreting the analysis of absolute and relative changes together provides a clear sense of overall progress.

The relative rate of change $(\delta)$ is computed for the MPI (and similarly for $H$, and $A$ which are not presented) as

$$
\delta M P I=\frac{M P I\left(X_{t^{2}}\right)-M P I\left(X_{t^{1}}\right)}{M P I\left(X_{t^{1}}\right)} \times 100
$$

The absolute and relative changes, however, are not comparable for different countries when the reference periods are of different length. To compare the rates of poverty reduction across countries that have different period of references, annualized changes are used. The annualized absolute rate of change $(\bar{\Delta})$ is the difference in the MPI between two periods divided by the difference in the two time periods $\left(t^{2}-t^{1}\right)$ and is computed for the MPI as

$$
\bar{\Delta} M P I=\frac{M P I\left(X_{t^{2}}\right)-M P I\left(X_{t^{1}}\right)}{t^{2}-t^{1}} .
$$

The annualized relative rate of change $(\bar{\delta})$ is the compound rate of reduction in the MPI per year between the initial and the final periods, and is computed for the MPI as 


$$
\bar{\delta} M P I=\left[\left(\frac{M P I\left(X_{t^{2}}\right)}{M P I\left(X_{t^{1}}\right)}\right)^{\frac{1}{t^{2}-t^{1}}}-1\right] \times 100
$$

The same formula can be used to compute and report annualized changes in the other partial indices, namely $H, A$, censored headcounts, or percent contributions. And all of these formulas may be used for MPI or for destitution measures.

The reductions in MPI can be broken down by dimensions. An analysis of changes in MPI considers both changes in the raw or uncensored headcount ratios $\left(h_{j}\right)$ and in the censored headcount ratios $\left(h_{j}(k)\right)$. The changes in censored headcount ratios depict changes in deprivations among the poor.

Changes in the national MPI can be decomposed by subnational regions, ethnic groups, or other population subgroups. That is, poverty in each period can be expressed as: $\operatorname{MPI}=\sum_{\ell=1}^{m} v^{\ell} \operatorname{MPI}\left(X^{\ell}\right)$, where $\operatorname{MPI}\left(X^{\ell}\right)$ and $v^{\ell}=n^{\ell} / n$ denote the MPI and the population share of subgroup $\ell$, respectively. It can be extremely useful to analyse poverty changes by population subgroups, to see if the poorest subgroups reduced poverty faster than less poor subgroups, and to see the dimensional composition of reduction across subgroups (Alkire and Seth 2013, Alkire and Roche 2013, Alkire Roche and Vaz 2014). Population-shares for each time period must be analysed alongside subgroup trends in order to take into account demographic shifts such as migration or population growth.

Changes in inequality over time has been computed by applying the formulae presented in Section 4 for each period and then applying the annualized and non-annualized changes over time as introduced earlier in this section for the MPI.

\section{Considerations by country}

This section comments on methodological issues in the 33 updated countries in the MPI 2014.

Afghanistan (MICS 2010/11): This represents a new country in the MPI Database. Sanitation facilities 'eco sanitation', 'single vault' and 'double vault' were considered as improved sanitation after consulting with UNICEF. Nutritional measurements were only performed in a very small subsample of women aged 15-49 and no children. Therefore, this information was disregarded and the MPI was computed with the remaining nine indicators.

Bangladesh (DHS 2011): Nutritional information was collected for every child under 5 and every evermarried women aged 12-49. In addition, in the households selected for male interviews (i.e. one in every three households), anthropometrics were taken for (i) ever-married women above 50; (ii) nevermarried women above 35; (iii) ever-married men aged 15-34; and (iv) all men above 35. All available information per household was used in the nutritional indicator, although this varied. No information on ownership of a car was available in the data. According to the published figure, MPI fell from 0.289 to 0.253 between 2007 and 2011, but when adjusted for comparability, MPI figures show a higher fall from 0.306 to $0.245 .^{5}$

\footnotetext{
5 There seems to be a significant increase in the proportion of people in households in which there is a school-aged child not attending school from previous MPI rounds (from $9.9 \%$ to $15 \%$ ). However, this is due to methodological differences when creating this indicator. The figures included in the MPI 2013 were based on Bangladesh's DHS 2007 data. Only people indicating that they have some level of schooling were asked in 2007 whether they attended school. School attendance was not assessed for those with no level of education (including school-aged children), and therefore they were not considered in the school attendance indictor. In the MPI 2014 we are
} 
Belize (MICS 2011): The MICS conducts anthropometric measures for all children under five, including those whose mothers may have died or are living elsewhere.

Bosnia and Herzegovina (MICS 2011/12): Anthropometric measures are available for all children under five, including those whose mothers may have died or are living elsewhere. There is no information on child mortality. Following our guidelines to compute subnational figures (Alkire, Roche and Seth 2011), subnational results are not presented for this country since the headcount of multidimensional poverty is below $1.5 \%$.

Burundi (DHS 2010): Anthropometrics were taken for a subsample; i.e. half of the households. Following guidelines from the Methodological Note 2013 (Alkire, Conconi and Roche 2013), the MPI estimation is based on this subsample. Results for the MPI 2014 are not comparable with those from previous rounds, computed based on a different survey, the MICS 2005, which was additionally lacking nutritional information.

Cameroon (DHS 2011): Anthropometrics were taken for a subsample; i.e. half of the households. Following guidelines from the Methodological Note 2013 (Alkire, Conconi and Roche 2013), the MPI estimation is based on this subsample. According to the published figure, MPI fell from 0.287 to 0.248 between these 2004 and 2011, but when adjusted for comparability, MPI figures show a fall from 0.298 to 0.248 .

Central African Republic (MICS 2010): This represents a country in the MPI Database that had been reported in 2010 and 2011 but dropped in 2013 because its data were 2000. Anthropometric measures are available for all children under five, including those whose mothers may have died or are living elsewhere. Following the survey report, "Puits à pompe (busé ou non)" was considered as an improved source of water. The survey is representative nationally, urban/rural and for 16 of the prefectures. However, one additional prefecture Vakaga ( $1 \%$ of total population in the country) is not representative due to safety issues. This prefecture was dropped without loss of generality in our findings. Robustness checks were performed, which show no impact of dropping this region on the MPI or on particular indicators.

Congo, Republic of (DHS 2011/12): Anthropometrics were taken for a subsample; i.e. half of the households. Following guidelines from the Methodological Note 2013 (Alkire, Conconi and Roche 2013), the MPI estimation is based on this subsample. Time necessary to obtain safe drinking water is now available. The DHS 2009 used in previous rounds did not have this information and therefore, though the proportion of household using each type of water facility was very similar to that in the DHS 2011/12, adding information on time to collect the water affects the results increasing the percentage of deprived individuals. Results for the MPI 2014 are not comparable with those from previous rounds, computed based on the DHS 2009 which was lacking information on nutrition.

Cote d'Ivoire (DHS 2011/12): Anthropometrics were taken for a subsample; i.e. half of the households. Following guidelines from the Methodological Note 2013 (Alkire, Conconi and Roche 2013), the MPI estimation is based on this subsample. There is a large proportion of eligible children for whom nutrition information is missing: 1044 out of $4337(24 \%)$ - 849 of these 1044 children are not even included in the children recode (KR). However, since children's nutritional information is combined with BMI measurements for women and men in the household, the percentage of missing information for the final household nutrition indicator is small (2.74\%). Results for the MPI 2014 are

considering children with no education as not attending school, and therefore deprived in this indicator. Following the same criteria, the percentage of deprived people would have been $17.7 \%$, showing then a decrease by 2011 . 
not comparable with those from previous rounds, computed based on the DHS 2005 which was lacking information on nutrition and cooking fuel.

Gabon (DHS 2012): Gabon had been previously dropped due to old data, and now has been re-added to the MPI Database. Anthropometrics were taken only for a subsample of the households; i.e. two thirds of the households. Following guidelines from the Methodological Note 2013 (Alkire, Conconi and Roche 2013), the MPI estimation is based on this subsample. The categories 'Village hydraulics' and 'Other protected well' were considered as improved sources for drinking water. Following the survey report, households using 'sawdust' or 'wood chips' as cooking fuel were considered deprived in this indicator. The changes over time figures were computed using information from DHS 2000. The 2012 MPI adjusted for comparability is 0.075 .

Ghana (MICS 2011): Anthropometric measures are available for all children under five, including those whose mothers may have died or are living elsewhere. Results for the MPI 2014 are not comparable with those from previous rounds, computed based on a different survey, the DHS 2008. Therefore, these results were not used in the analysis over time. The changes over time figures refer to the period between 2003 and 2008 .

Guinea-Bissau (MICS 2006): This represents a new country in the MPI Database. Anthropometric measures are available for all children under five, including those whose mothers may have died or are living elsewhere. It is worth mentioning that nine clusters in the north of the Cacheu region could not be reached due to security reasons. Following our guidelines to compute subnational figures (Alkire, Roche and Seth 2011), subnational results are not presented since they could be biased.

Haiti (DHS 2012): Following the survey report, the category 'Sales company of water' was considered as an improved source of water. Similarly, 'Mobile chemical toilet' was considered a non-improved sanitation facility. Results for the MPI 2014 are not comparable with those from previous rounds, computed based on the DHS 2005/06 since the treatment of nutritional subsamples was different. As stated in the 2013 Methodological Note, for current updates of the MPI figures we use the information of those households that are included in the nutritional subsample (i.e. two thirds of the households). In previous rounds of the MPI (2010 and 2011) the subsamples in nutritional data were not taken into account. ${ }^{6}$ According to the published figure, MPI fell from 0.299 to 0.248 between these 2005/6 and 2012, but when adjusted for comparability, MPI figures show a higher fall from 0.335 to 0.248 .

Honduras (DHS 2011/12): Following the survey report, the facilities 'Flush toilet with connection to open water' and 'Latrine with siphon' were considered improved, while 'Latrine with connection to open water' was considered an unimproved facility. There is no information on access to electricity.

Indonesia (DHS 2012): There is no information on nutrition for either member of the households. The MPI figures can be directly compared across time.

Iraq (MICS 2011): Anthropometric measures are available for all children under five, including those whose mothers may have died or are living elsewhere. 'Reverse osmosis' was considered as an improved source of water.

\footnotetext{
6 The proportion of people living in household with at least one undernourished member seems to have risen from 13.1\% in 2005/06 to $20.8 \%$ in 2012. However, as explained in the main text, these figures are not comparable. Should the sample in 2005/06 been restricted to households included in the nutritional subsample, the proportion of deprived people would have been $26.8 \%$, thus showing an improvement by 2012 .
} 
Kazakhstan (MICS 2010/11): Anthropometric measures are available for all children under five, including those whose mothers may have died or are living elsewhere. Following our guidelines to compute subnational figures (Alkire, Roche and Seth 2011), subnational results are not presented for this country since the headcount of multidimensional poverty is below $1.5 \%$.

Lao PDR (MICS-DHS 2011/12): Anthropometric measures are available for all children under five, including those whose mothers may have died or are living elsewhere. Results for the MPI 2014 are not comparable with those from previous rounds, computed based on the MICS 2006 which was lacking information on child mortality.

Macedonia, TFYR of (MICS 2011): Anthropometric measures are available for all children under five, including those whose mothers may have died or are living elsewhere. There is no information on child mortality available at the national level, but only for Roma settlements. Thus, the MPI was computed based on the remaining nine indicators. This implies that the MPI 2014 findings are not comparable to those from previous rounds, computed based on the MICS 2005/06 which had information on child mortality for the whole sample. Following our guidelines to compute subnational figures (Alkire, Roche and Seth 2011), subnational results are not presented for this country since the headcount of multidimensional poverty is below $1.5 \%$.

Mexico (ENSANUT 2012): Anthropometric measures were taken randomly, whenever possible given the household structure, for one child under 5, one child aged 5-9, one teenager aged 10-15, and one adult above 15 per household. All information available for each household was used to compute the nutritional indicator. Results are not directly comparable to those from previous rounds based on the ENSANUT 2006.

Mozambique (DHS 2011): Results for the MPI 2014 are not comparable with those from previous rounds, computed based on the DHS 2009 which was actually an Aids Indicator Survey (AIS) with a different focus and was lacking nutritional information. In the analysis over time we compared 2003 and 2011. The $2011 \mathrm{MPI}$ adjusted for comparability is 0.393 .

Nicaragua (DHS 2011/12): Every woman aged 15-49 is eligible but only one of them per household is randomly selected for an interview and anthropometrics. In turn, every child under 5 born from interviewed women is eligible for anthropometrics. ${ }^{7}$ Only one third of households are selected for men interviews, in which only one man aged 15-59 is randomly selected.

Niger (DHS 2012): Results for the MPI 2014 are not comparable with those from previous rounds, computed based on the DHS 2005/06 since the treatment of nutritional subsamples was different. As stated in the 2013 Methodological Note, for current updates of the MPI figures we use the information of those households that are included in the nutritional subsample (i.e. half of the households in the case of the DHS 2012). In previous rounds of the MPI (2010 and 2011) the subsamples in nutritional data were not taken into account. It is worth mentioning that, due to difficulties in access, the department Bilma in the region d'Agadez $(0.15 \%$ of the total population in Niger) was excluded from the sample. In addition, according to UNESCO, the compulsory entry age for primary school switched from 7 to 6, which affects the child school attendance indicator. According to the published figure, MPI fell from 0.642 to 0.605 between these 2006 and 2012, but when adjusted for comparability, MPI figures show a higher fall from 0.696 to 0.621 .

\footnotetext{
7 This contrasts with other DHS, in which all children under 5 are eligible. In this case, only those born from the randomly selected woman in each household are interviewed and measured.
} 
Nigeria (MICS 2011): Anthropometric measures are available for all children under five, including those whose mothers may have died or are living elsewhere. Following the survey report, 'Sachet/pure water' was considered an unimproved source of drinking water. Results for the MPI 2014 are not comparable with those from previous rounds, computed based on a different survey, the DHS 2008. Therefore, the MPI 2014 results were not used in the analysis over time. The changes over time figures refer to the period between 2003 and 2008.

Pakistan (DHS 2012/13): Following the survey report, 'Hand pump' and 'Filtration plant' are both considered as improved sources of water. Results for the MPI 2014 are not comparable with those from previous rounds, computed based on the DHS 2006/07 which was lacking nutritional information. Also, as stated in the 2013 Methodological Note, for current updates of the MPI figures we use the information of those households that are included in the nutritional subsample (i.e. one third of the households). In addition, the sample excludes the regions Azad Jammu and Kashmir, the Federally Administered Tribal Areas, and military restricted and protected areas of Pakistan. Also, out of the 500 Primary Sampling Units two from Balochistan couldn't be covered due to security issues. According to the published figure, MPI fell from 0.264 to 0.230 between these 2006/7 and 2012/13, but when adjusted for comparability, MPI only fell to 0.235 .

Serbia (MICS 2010): Anthropometric measures are available for all children under five, including those whose mothers may have died or are living elsewhere. Results for the MPI 2014 are not comparable with those from previous rounds, computed based on the MICS 2005/06 which was lacking information on child mortality. Following our guidelines to compute subnational figures (Alkire, Roche and Seth 2011), subnational results are not presented for this country since the headcount of multidimensional poverty is below $1.5 \%$.

Sierra Leone (MICS 2010): Results for the MPI 2014 are not comparable with those from previous rounds, computed based on a different survey, the DHS 2008. In particular, anthropometric measures are now available for all children under five, including those whose mothers may have died or are living elsewhere. The DHS 2008 also had information on women's BMI which was considered for the final nutritional indicator (without taken into account the nutritional subsample).

South Africa (NIDS 2012): Anthropometric measures are available for children under 15 and adults (men and women). All information available for each household was used to compute the nutritional indicator. Results for the MPI 2014 are not comparable with those from previous rounds, computed based on the NIDS 2008 which was lacking information on flooring.

Suriname (MICS 2010): Anthropometric measures are available for all children under five, including those whose mothers may have died or are living elsewhere. Results for the MPI 2014 are not comparable with those from previous rounds, computed based on the MICS 2006, since we are now lacking information on child mortality.

Tajikistan (DHS 2012): Results for the MPI 2014 are not comparable with those from previous rounds, computed based on a different survey, the MICS $2006 .{ }^{8}$

\footnotetext{
8 The difference in the source of information is especially relevant in the case of the nutritional indicator. The proportion of people living in households with at least one undernourished member seems to have increased from $11.5 \%$ in 2005 to $26.6 \%$ in 2010 . However, the MICS 2005 only assessed the nutritional situation of children under five and over $44 \%$ of the (weighted) sample did not have eligible children so they were assumed to be non-deprived. For the MPI 2014 we are using the DHS 2012 we has nutritional information for children under five and women aged 15-49. In addition, only 3.1\% of the (weighted) sample has no eligible women and children, and thus the assumption of no deprivation is not as strong.
} 
Togo (MICS 2010): Anthropometric measures are available for all children under five, including those whose mothers may have died or are living elsewhere. Following the report, 'rainwater' was considered an unimproved source of water.

Tunisia (MICS 2011/12): Anthropometric measures are available for all children under five, including those whose mothers may have died or are living elsewhere. Results for the MPI 2014 are not comparable with those from previous rounds, computed based on a different survey, the WHS 2003, which was lacking information on school attendance. Child mortality is only assessed for evermarried women. Thus, those never married are considered as not eligible for questions on child mortality and assumed to be non-deprived. Following our guidelines to compute subnational figures (Alkire, Roche and Seth 2011), subnational results are not presented for this country since the headcount of multidimensional poverty is below $1.5 \%$. 


\section{Cited References}

Alkire, S., A. Conconi, and S. Seth (2014): 'Multidimensional Destitution: an ordinal counting methodology for constructing linked subsets of the poor'. OPHI Research in Progress $42 a$.

Alkire, S., A. Conconi, and J.M. Roche (2013): "Multidimensional Poverty Index 2013: Brief Methodological Note and Results", Oxford Poverty and Human Development Initiative, Oxford University. ophi.qeh.ox.ac.uk

Alkire, S. and Foster, J. E. (2007). "Counting and Multidimensional Poverty Measures," OPHI Working Paper 7. Oxford Poverty and Human Development Initiative, University of Oxford.

Alkire, S. and Foster, J. E. (2011). "Counting and Multidimensional Poverty Measurement," Journal of Public Economics, 95(7): 476-487.

Alkire, S. and Roche, J.M. (2013). "How Successful are Countries in Reducing Multidimensional Poverty? Insights from Inter-Temporal Analyses of Twenty-two Countries." mimeo

Alkire, S., Roche, J.M., Santos, M.E., and Seth, S. (2011). "Multidimensional Poverty Index 2011: Brief Methodological Note." Oxford Poverty and Human Development Initiative, University of Oxford.

Alkire, S. and Santos, M. E. (2010), "Acute Multidimensional Poverty: A New Index for Developing Countries," OPHI Working Paper 38. Oxford Poverty and Human Development Initiative, University of Oxford.

Alkire, S., Roche, J. M., and Seth S. (2011). 'Sub-national Disparities and Inter-temporal Evolution of Multidimensional Poverty across Developing Countries'. OPHI Research in Progress 32a.

Alkire, S., Roche, J. M., and Vaz, A. (2014). 'Multidimensional Poverty Dynamics: Methodology and Results for 34 Countries'. OPHI Research in Progress 41 a.

Alkire, S., Roche, J. M., Santos, M. E., and Seth, S. (2011). 'Multidimensional Poverty Index 2011: Brief Methodological Note'. OPHI Briefing 07.

Alkire, S. and Santos, M. E. (2013), "Measuring Acute Poverty Using the Multidimensional Poverty Index: Robust Comparisons and Future Prospects," OPHI Working Paper 59. Oxford Poverty and Human Development Initiative, University of Oxford.

Alkire, S., Santos, M. E., Seth, S., and Yalonetzky, G. (2010). 'Is the Multidimensional Poverty Index Robust to Different Weights?' OPHI Research Paper 22a.

Alkire, S. and Seth, S. (2013). "Multidimensional Poverty Reduction in India between 1999 and 2006: Where and How?" OPHI Working Paper 60. Oxford Poverty and Human Development Initiative, University of Oxford.

Oxford Poverty and Human Development Initiative (2013). "Multidimensional Poverty Index Data Bank." Oxford Poverty and Human Development Initiative, University of Oxford. Available at: www.ophi.org.uk/multidimensional-poverty-index/mpi-country-briefings/.

UNDESA (2013). United Nations, Department of Economic and Social Affairs, Population Division (June). World Population Prospects: The 2012 Revision, DVD Edition.

UNDP (2010). Human Development Report 2010: The Real Wealth of Nations: Pathways to Human Development. New York: Palgrave Macmillan.

Seth, S. and Alkire, S. (2013). 'Measuring and Decomposing Inequality among the Multidimensionally Poor using Ordinal Variables: A Counting Approach'. OPHI Working paper 68. 
Rutstein, S.O. and Rojas, G. (2006). "Online Guide to DHS Statistics," Demographic and Health Surveys. http://legacy.measuredhs.com/help/Datasets/index.htm Accessed January 2013.

WHO Multicentre Growth Reference Study Group (2006). WHO Child Growth Standards: Length/Height-for-Age, Weight-for-Age, Weight-for-Length, Weight-for-Height and Body Mass Index-for-Age: Methods And Development. Geneva: World Health Organization. http://www.who.int/childgrowth/publications/en. 
Table Annex A.1: The dimensions, indicators, deprivation thresholds and weights of the MPI

\begin{tabular}{|c|c|c|c|c|}
\hline Dimension & Indicator & Deprived if... & Related to... & $\begin{array}{l}\text { Relative } \\
\text { Weight }\end{array}$ \\
\hline \multirow{2}{*}{ Education } & $\begin{array}{l}\text { Years of } \\
\text { Schooling }\end{array}$ & $\begin{array}{l}\text { No household member has completed five } \\
\text { years of schooling. }\end{array}$ & MDG2 & $1 / 6$ \\
\hline & $\begin{array}{l}\text { Child School } \\
\text { Attendance }\end{array}$ & $\begin{array}{l}\text { Any school-aged child is not attending school } \\
\text { up to class } 8 .\end{array}$ & MDG2 & $1 / 6$ \\
\hline \multirow[b]{2}{*}{ Health } & Child Mortality & Any child has died in the family. & MDG4 & $1 / 6$ \\
\hline & Nutrition & $\begin{array}{l}\text { Any adult or child for whom there is nutritional } \\
\text { information is malnourished.* }\end{array}$ & MDG1 & $1 / 6$ \\
\hline \multirow{6}{*}{ Living Standard } & Electricity & The household has no electricity. & & $1 / 18$ \\
\hline & $\begin{array}{l}\text { Improved } \\
\text { Sanitation }\end{array}$ & $\begin{array}{l}\text { The household's sanitation facility is not } \\
\text { improved (according to MDG guidelines), or it } \\
\text { is improved but shared with other } \\
\text { households. }^{* *}\end{array}$ & MDG7 & $1 / 18$ \\
\hline & $\begin{array}{l}\text { Safe Drinking } \\
\text { Water }\end{array}$ & $\begin{array}{l}\text { The household does not have access to safe } \\
\text { drinking water (according to MDG guidelines) } \\
\text { or safe drinking water is more than a } 30 \text {-minute } \\
\text { walk from home, roundtrip.*** }\end{array}$ & MDG7 & $1 / 18$ \\
\hline & Flooring & The household has a dirt, sand or dung floor. & & $1 / 18$ \\
\hline & Cooking Fuel & $\begin{array}{l}\text { The household cooks with dung, wood or } \\
\text { charcoal. }\end{array}$ & MDG7 & $1 / 18$ \\
\hline & $\begin{array}{c}\text { Assets } \\
\text { Ownership }\end{array}$ & $\begin{array}{l}\text { The household does not own more than one } \\
\text { radio, TV, telephone, bike, motorbike or } \\
\text { refrigerator and does not own a car or truck. }\end{array}$ & MDG7 & $1 / 18$ \\
\hline
\end{tabular}

Note: MDG1 is Eradicate Extreme Poverty and Hunger; MDG2 is Achieve Universal Primary Education; MDG4 is Reduce Child Mortality; MDG7 is Ensure Environmental Sustainability.

${ }^{+}$Data Source for age children start school: United Nations Educational, Scientific and Cultural Organization, Institute for Statistics database, Table 1. Education systems [UIS, http://stats.uis.unesco.org/unesco/TableViewer/tableView.aspx?ReportId=163 ].

${ }^{*}$ Adults are considered malnourished if their BMI is below $18.5 \mathrm{~m} / \mathrm{kg}^{2}$. Children are considered malnourished if their $\mathrm{z}$-score of weight-for-age is below minus two standard deviations from the median of the reference population.

${ }^{* *}$ A household is considered to have access to improved sanitation if it has some type of flush toilet or latrine, or ventilated improved pit or composting toilet, provided that they are not shared.

${ }^{* * *} \mathrm{~A}$ household has access to clean drinking water if the water source is any of the following types: piped water, public tap, borehole or pump, protected well, protected spring or rainwater, and it is within a distance of 30 minutes' walk (roundtrip).

Source: Alkire and Santos (2010). For details on the rationale behind each indicator, please see Alkire and Santos (2010, 2013). 
Table Annex A.2: The dimensions, indicators, deprivation thresholds and weights of Destitution

\begin{tabular}{|c|c|c|c|c|}
\hline Dimension & Indicator & Deprived if... & Related to... & $\begin{array}{l}\text { Relative } \\
\text { Weight }\end{array}$ \\
\hline \multirow{2}{*}{ Education } & $\begin{array}{l}\text { Years of } \\
\text { Schooling }\end{array}$ & $\begin{array}{l}\text { No household member has completed at least } \\
\text { one year of schooling }(>=1) \text {. }\end{array}$ & MDG2 & $1 / 6$ \\
\hline & $\begin{array}{l}\text { Child School } \\
\text { Attendance }\end{array}$ & $\begin{array}{l}\text { No child is attending school up to the age at } \\
\text { which they should finish class } 6 \text {. }\end{array}$ & MDG2 & $1 / 6$ \\
\hline \multirow[b]{2}{*}{ Health } & Child Mortality & 2 or more children have died in the household & MDG4 & $1 / 6$ \\
\hline & Nutrition & $\begin{array}{l}\text { Severe undernourishment of any adult } \\
\left(\mathrm{BMI}<17 \mathrm{~kg} / \mathrm{m}^{2}\right) \text { or any child } \\
(-3 \text { standard deviations from the median). }\end{array}$ & MDG1 & $1 / 6$ \\
\hline \multirow{6}{*}{ Living Standard } & Electricity & The household has no electricity (no change). & & $1 / 18$ \\
\hline & $\begin{array}{l}\text { Improved } \\
\text { Sanitation }\end{array}$ & There is no facility (open defecation). & MDG7 & $1 / 18$ \\
\hline & $\begin{array}{l}\text { Safe Drinking } \\
\text { Water }\end{array}$ & $\begin{array}{l}\text { The household does not have access to safe } \\
\text { drinking water, or safe water is more than a } 45 \text { - } \\
\text { minute walk (round trip). }\end{array}$ & MDG7 & $1 / 18$ \\
\hline & Flooring & $\begin{array}{l}\text { The household has a dirt, sand, or dung floor } \\
\text { (no change). }\end{array}$ & & $1 / 18$ \\
\hline & Cooking Fuel & $\begin{array}{l}\text { The household cooks with dung or wood } \\
\text { (coal/lignite/charcoal are now non- } \\
\text { deprived). }\end{array}$ & MDG7 & $1 / 18$ \\
\hline & $\begin{array}{c}\text { Assets } \\
\text { Ownership }\end{array}$ & $\begin{array}{l}\text { The household has no assets (radio, mobile } \\
\text { phone, etc.) and no car. }\end{array}$ & MDG7 & $1 / 18$ \\
\hline
\end{tabular}




\section{OPHI's Global MPI Data Bank}

www.ophi.org.uk/multidimensional-poverty-index/

OPHI's Global MPI Databank contains a wealth of resources on multidimensional poverty in more than 100 developing countries, enabling users to see how poverty is experienced in different parts of the world, zoom in on sub-national regions, or explore the character of poverty by different indicators. Follow the links below to find out more.

$\checkmark \quad$ MPI Country Briefings: Short, country-specific summaries on the results of the MPI analyses. A number of the briefings include data at the sub-national level.

$\checkmark \quad$ MPI Interactive Databank: An interactive databank that enables you to navigate the world according to the MPI as a whole or by individual dimensions and indicators of MPI poverty. You can zoom in on individual countries, and choose whether you want to see how multidimensional poverty has changed over time.

$\checkmark \quad$ MPI 2014 Papers: The key academic papers from this year's analysis, including Seth and Alkire (2014) 'Measuring and Decomposing Inequality among the Multidimensionally Poor Using Ordinal Data: A Counting Approach'; Alkire, Roche and Vaz (2014) 'Multidimensional Poverty Dynamics: Methodology and Results for 34 Countries' and Alkire, Conconi and Seth (2014) 'Measuring Destitution in Developing Countries: An Ordinal Approach for Identifying Linked Subsets of the Multidimensionally Poor'.

$\checkmark \quad$ MPI Data Tables - Main MPI Results: A table which presents the basic MPI results and sorts 108 countries from low to high.

$\checkmark \quad$ MPI Data Tables - MPI at the Sub-national Level: This table reports the MPI, its two components - the Headcount Ratio and the Intensity of Deprivation among the poor - and other indicators of multidimensional poverty for nearly 800 regions of 69 countries.

$\checkmark \quad$ MPI Data Tables - MPI over Time: This table shows the value and confidence intervals for the main MPI results of 34 countries for which we have comparable data over time.

$\checkmark \quad$ MPI Methodology: OPHI's MPI methodological notes explain how the global MPI is calculated and shares the updates that have taken place since it was first reported in 2010.

$\checkmark \quad$ MPI Resources: MPI publications collected in one place, including working papers and exchanges, and training material for producing a global or national MPI.

$\checkmark \quad$ MPI Background: A brief history of the MPI, including how it came to be developed for publication in UNDP's Human Development Report, and how it is being used now.

$\checkmark \quad$ MPI Case Studies: Stories of people who are poor according to the MPI in their country: their hopes, strengths and challenges.

$\checkmark \quad$ Making your own MPI: Adaptations of the global MPI for other purposes, such as national poverty measurement, targeting, child poverty measurement and empowerment.

$\checkmark \quad$ Online training portal: Resources on multidimensional measurement techniques, including video and audio files, lecture slides, exercises and reading lists.

Citation of this paper: Alkire, S., Conconi, A. and Seth, S. (2014). "Multidimensional Poverty Index 2014: Brief Methodological Note and Results." 